Research Article

\title{
Experimental Study of the Dynamic Tensile Mechanical Properties of a Coal Sandstone Disc with a Central Hole
}

\author{
Jiehao Wu (iD, Qi Zong, and Ying Xu \\ School of Civil Engineering and Architecture, Anhui University of Science and Technology, Huainan, Anhui 232001, China \\ Correspondence should be addressed to Jiehao Wu; jhwu1991@163.com
}

Received 22 September 2020; Revised 11 November 2020; Accepted 13 November 2020; Published 28 November 2020

Academic Editor: Zhijie Wen

Copyright (c) 2020 Jiehao Wu et al. This is an open access article distributed under the Creative Commons Attribution License, which permits unrestricted use, distribution, and reproduction in any medium, provided the original work is properly cited.

\begin{abstract}
Deep mine rocks are often subjected to rock burst induced by dynamic load. The existence of initial holes will reduce the mechanical properties of rocks and affect the stability and safety of the tunnel excavating. In order to study the effect of the ratios of inner and outer diameter on disc specimen dynamic mechanical properties and failure modes, we use cylindrical sandstone specimens of $\Phi 50 \times 25 \mathrm{~mm}$ to process center holes of different diameters, and a series of dynamic splitting test were carried out with a system of split Hopkinson pressure bar (SHPB) with the diameter of $\Phi 50 \mathrm{~mm}$ when the pressure is $0.15 \mathrm{MPa}, 0.3 \mathrm{MPa}$, and $0.5 \mathrm{MPa}$. The results show that (1) the dynamic tensile stress-time-history curve exhibited double peak phenomena, and the second peak value is less than the first peak value, (2) the dynamic tensile stress peaks decrease nonlinearly with the increasing of the ratios of inner and outer diameter, and the dependence is more obvious when the pressure is higher, and (3) there is a tensile crack running along the loading direction in the failure modes of the five samples with the ratio of inner to outer diameter under three kinds of impact pressure. Under the same impact pressure, when the ratio of inner diameter to outer diameter is greater than the critical ratio of inner diameter to outer diameter, there is an obvious empty hole effect; that is, the sample develops secondary tensile cracks that develop from the upper and lower ends of the pore disc to the center of the inner hole. With the increase of the ratio of inner diameter to outer diameter, the width of the penetration crack increases. With the increase of impact pressure, the critical ratio of inner diameter to outer diameter decreases gradually. The research results have certain significance for understanding the mechanical properties of porous rocks.
\end{abstract}

\section{Introduction}

With increasingly deep coal mining, accidents due to typical dynamic hazards such as rock burst are prone to occur under dynamic loads such as engineering blasting. These hazards have the characteristics of being sudden, rapid, and violent and have a serious impact on coal mine production safety [1]. Natural rocks are product of nature. They contain a wide range of initial defects (microcracks and microcavities) with different sizes, different occurrences, and different properties. These initial defects constitute weak points in the rocks and significantly reduce the strength and increase the ductility of the rocks. Macroscopically, these rocks are discontinuous, heterogeneous, anisotropic, and highly nonlinear. Their deformation and failure processes are coupled, multiscale damage evolution and macroinelastic deformation. The evolution process is the precursor and prerequisite for the localization and instability of the rock mass, and it plays a decisive role in the ultimate failure mode of the rock mass [2-4]. Specifically, these initial defects are considered to be especially important structures that control the strength of a rock. Under stress, local stress concentration will occur around the initial defects. Since the tensile strength of the rock is much lower than its compressive strength, tensile cracks may form, resulting in the brittle failure of the rock mass [5]. Under dynamic loading, the small defects in the rock mass will be activated and will connect to form a large connected discontinuous surface [6]. Therefore, the mechanical response of the rock to dynamic loading is a key to determining the stability of the rock structures surrounding mine tunnels and the safety and efficiency of resource mining. Therefore, it is of great 
importance to study the dynamic tensile mechanical behavior of preholed rocks from deep mines. In previous studies, due to the difficulty of field testing, laboratory tests have been widely used as an effective approach.

Because rock is a typical brittle material, its tensile mechanical properties are quite difficult to measure using a direct tensile stressing method. Therefore, most of these properties are measured through indirect testing. One of these methods is the Brazilian disc test, which is a commonly used indirect testing method. In order to reduce the stress concentration at the loading ends, researchers use ringshaped specimens and the Brazilian disc test to determine the tensile strength of the rock. In such a test, a disc with a central hole is subjected to radial compression [7-9]. In 1965, Hobbs [10] proposed a formula for calculating the tensile strength based on the linear elasticity during ring split testing. Since then, many studies have used splitting tests of ring specimens and have achieved reasonable results. Chen and Hsu [11] conducted diametric compression tests and BEM (boundary element method) analysis to study the stress distribution around the central hole in a ring specimen and analyzed the effects of the inclination angle of the foliation and the hole size on the tensile strength of marble. Zhu et al. [12] used the RFRA software to simulate the radial compression testing of ring specimens and analyzed the effects of the inner hole diameter on the rock fracture mode and tensile strength. You et al. [13] conducted Brazilian disc tests on ring specimens of rock and found that Hobbs' tensile strength formula did not describe the actual situation. They proposed a formula for calculating the peak stress of a specimen and used it to evaluate the effect of the inner hole diameter on the tensile strength of a ring specimen. Wu et al. $[14,15]$ conducted Brazilian disc tests on sandstone ring specimens and analyzed the effects of the inner hole diameter on the specimens' mechanical properties. Yang [16] used the plastic flow code (PFC) model to simulate the Brazilian disc testing process for a single-hole disc specimen and analyzed the characteristics of the rock's tensile strength, the number of microcracks, and the failure mode. Bai et al. $[17,18]$ studied the fracture process and mechanical properties of a rock disk with a central hole under static load through numerical simulation.

However, previous studies have mainly focused on static loading or quasi-static loading, which is not suitable for common rock dynamic loading environments in deep mine construction projects. Few studies have been conducted on this topic. Li et al. [19-21] conducted static and dynamic splitting tests on rock ring specimens and analyzed the effects of the inner hole diameter on the dynamic tensile strength, peak stress, and failure mode of the rock.

In order to further study the effects of holes and impact pressure on the dynamic tensile mechanical properties and failure modes of rocks, in this study, the SHPB (Split Hopkinson Pressure Bar) was used to perform dynamic Brazilian disc tests on disc specimens with central holes with different inner-to-outer diameter ratios under gas gun pressures of $0.15 \mathrm{MPa}, 0.3 \mathrm{MPa}$, and $0.5 \mathrm{MPa}$, and the variations in the dynamic peak stress and failure modes of the rock specimens were analyzed using an ultrahigh dynamic strainmeter.

\section{Experimental Methods and Preparation}

2.1. Specimen Preparation. In this study, sandstone samples collected from an $880 \mathrm{~m}$ deep underground tunnel in the Zhangji coal mine in Huainan City, Anhui Province, were tested. The main components of the sandstone were quartz, feldspar, and dolomite. The specific physical properties of the sandstone are presented in Table 1. Following the basic requirements of the International Society for Rock Mechanics (ISRM) [22], the diameter and height of each specimen were $50 \mathrm{~mm}$ and $25 \mathrm{~mm}$, respectively. The specimens are shown in Figure 1. Two types of specimens were used: (1) solid disc specimens and (2) ring specimens, that is, a disc containing a central hole. The ring specimens had inner diameter $d$ to the outer diameter $D, d / D$, and ratios of $0.08,0.12,0.16,0.2$, and 0.24 .

2.2. Splitting Test Principle under a Static Load. The Brazilian disc test is widely used to determine the tensile strengths of rocks due to the simplicity of its specimen preparation method. It serves as an alternative to direct uniaxial tensile testing. According to the ISRM [22], the indirect tensile strength of a solid disc specimen is

$$
\sigma=\frac{2 P}{\pi D L},
$$

where $P$ is the load applied to the specimen, $D$ is the diameter of the disc, and $L$ is the thickness of the specimen.

The peak stress $T T$ of a marble ring specimen can be calculated according to the following formula proposed by You et al. [13]:

$$
T T=\frac{2 P}{\pi(D-d) L},
$$

where $d$ is the diameter of the central hole of the ring.

Li et al. [20] validated (2) by conducting SHPB dynamic splitting tests on sandstone ring specimens. Thus, in this study, this equation was used to calculate the dynamic tensile peak stress of sandstone ring specimens.

2.3. Dynamic Test System and Principle. The tests were carried out using the $\Phi 50 \mathrm{~mm}$ SHPB test system at the School of Civil Engineering and Architecture, Anhui University of Science and Technology. The SHPB test system is shown in Figure 2. The striker, incident bar, and transmission bar of the system are all made of the same type of high-strength steel alloy, with the following properties: a density of $7800 \mathrm{~kg} / \mathrm{m}^{3}$, an elastic modulus of $210 \mathrm{GPa}$, Poisson's ratio of 0.30 , and a wave velocity of $5190 \mathrm{~m} / \mathrm{s}$. The impact generated using the tapered striker head achieves a slow increase in the incident wave front, which provides enough time for the sandstone specimen to reach uniform stress. The signals were collected in real time using the ultrahigh dynamic strainmeter and the strain gauges on the incident bar and the transmission bar [23]. The picture 
TABLE 1: Static mechanical properties of sandstone.

\begin{tabular}{lcccc}
\hline True density $\left(\mathrm{g} / \mathrm{mm}^{3}\right)$ & Longitudinal wave velocity $(\mathrm{m} / \mathrm{s})$ & Porosity $(\%)$ & Compressive strength $(\mathrm{MPa})$ & Tensile strength $(\mathrm{MPa})$ \\
\hline 2.53 & 3770 & 1.47 & 118.47 & 5.52
\end{tabular}

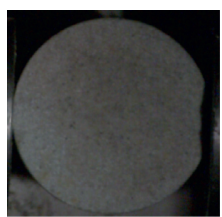

(a)

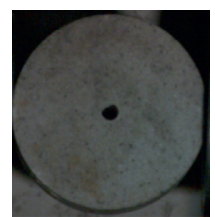

(b)

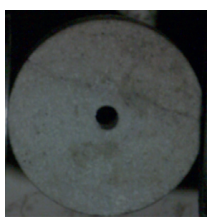

(c)

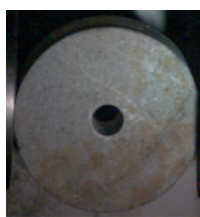

(d)

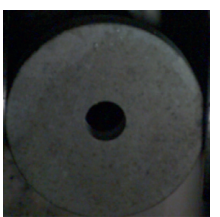

(e)

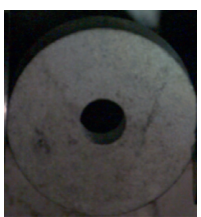

(f)

Figure 1: Sandstone specimens with precentral hole disc and complete disc: (a) $d / D=0$; (b) $d / D=0.08$; (c) $d / D=0.12$; (e) $d / D=0.2$; (f) $d / D=0.24$.

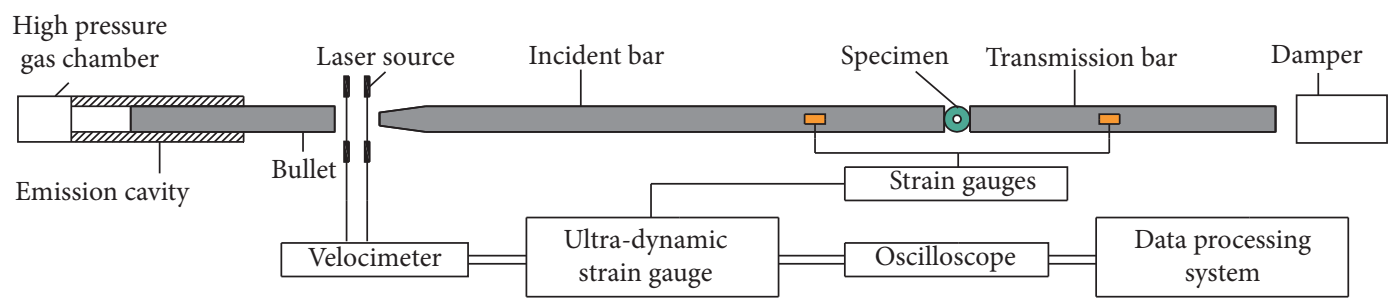

Figure 2: Schematic diagram of the SHPB test system.

frame of the HX-3 high-speed camera, which was used to record the crack propagation and dynamic failure processes, was set to $20000 \mathrm{fps}$.

According to the testing specifications recommended by the ISRM [24], the loading force on the specimen during the impact loading process was defined as follows:

$$
P(t)=\frac{1}{2} A_{0} E_{0}\left(\varepsilon_{\mathrm{i}}(t)+\varepsilon_{\mathrm{r}}(t)+\varepsilon_{\mathrm{t}}(t)\right) .
$$

When the specimen is in a state of stress equilibrium, the inertial effects can be ignored; that is,

$$
\varepsilon_{\mathrm{i}}(t)+\varepsilon_{\mathrm{r}}(t)=\varepsilon_{\mathrm{t}}(t),
$$

where $t$ is the loading time, $P(t)$ is the loading history, $A_{0}$ is the cross-sectional area of the test bar, $E_{0}$ is the elastic modulus of the test bar, and $\varepsilon_{\mathrm{i}}(t) \varepsilon_{\mathrm{r}}(t)$, and $\varepsilon_{\mathrm{t}}(t)$ are the incident strain, reflected strain, and transmitted strain, respectively. Substituting (4) into (3) yields

$$
P(t)=A_{0} E_{0} \varepsilon_{t}(t) .
$$

Thus, the dynamic tensile stress of a solid disc specimen under SHPB dynamic loading is defined as

$$
\sigma(t)=\frac{2 P(t)}{\pi D L}=\frac{2 A_{0} E_{0} \varepsilon_{t}(t)}{\pi D L} .
$$

The dynamic tensile stress of a sandstone ring specimen under SHPB dynamic loading is defined as

$$
\sigma(t)=\frac{2 P(t)}{\pi(D-d) L}=\frac{2 A_{0} E_{0} \varepsilon_{t}(t)}{\pi(D-d) L} .
$$

Finally, the dynamic peak stress of a sandstone ring specimen under SHPB dynamic loading is the maximum value of the dynamic tensile stress in the test state; that is, $\sigma=\max \{\sigma(t)\}$.

\section{Results and Analysis}

For the solid sandstone disc specimens and the sandstone ring specimens with five different $d / D$ values, the gas gun pressures were $0.15 \mathrm{MPa}, 0.3 \mathrm{MPa}$, and $0.5 \mathrm{MPa}$. To ensure that the impact velocity of each test was the same, the striker was restored to its original position before applying the load. The impact velocity of the specimen under different gas gun pressures was the same. The impact splitting tests were carried out on three specimens under the same set of conditions (four specimens were tested under partial conditions). A typical test result of these tests was selected. The test parameters and the typical test results are presented in Table 2. Within the scope of this test, the test data for the specimens with different $d / D$ values under the same gas gun pressure basically exhibited the same behavior, and the test data for the ring specimens with the same inner hole diameter under different gas gun pressures also basically exhibited the same behavior. Thus, the test data for the specimens with five different $d / D$ values, the solid disc specimens with a gas gun pressure of $0.3 \mathrm{MPa}$, and the test data for the ring specimens with $d / D=0.16$ at the three pressures were used for the analysis.

3.1. Stress Equilibrium Verification. Based on the electrical signals of the typical incident wave, the reflected wave, and the transmitted wave of a specimen acquired using the ultrahigh dynamic strainmeter, the typical stress equilibrium was obtained through signal conversion processing 
TABLE 2: Typical impact split test results of sandstorm specimens.

\begin{tabular}{|c|c|c|c|c|c|}
\hline $\begin{array}{l}\text { Samples } \\
\text { number }\end{array}$ & $\begin{array}{l}\text { Hole diameter } d \\
(\mathrm{~mm})\end{array}$ & $\begin{array}{c}\text { Ratios of inner and outer } \\
\text { diameter } d / D\end{array}$ & $\begin{array}{c}\text { Impact pressure } p \\
(\mathrm{MPa})\end{array}$ & $\begin{array}{l}\text { Impact velocity } v \\
(\mathrm{~m} / \mathrm{s})\end{array}$ & $\begin{array}{c}\text { Dynamic peak stress } \sigma \\
(\mathrm{MPa})\end{array}$ \\
\hline O1-1 & 0 & 0 & 0.15 & 3.585 & 17.36 \\
\hline O1-3 & 0 & 0 & 0.15 & 3.537 & 17.07 \\
\hline A1-1 & 4 & 0.08 & 0.15 & 3.494 & 14.29 \\
\hline A1-2 & 4 & 0.08 & 0.15 & 3.524 & 14.3 \\
\hline B1-1 & 6 & 0.12 & 0.15 & 3.44 & 13.71 \\
\hline $\mathrm{B} 1-3$ & 6 & 0.12 & 0.15 & 3.505 & 13.83 \\
\hline $\mathrm{C} 1-1$ & 8 & 0.16 & 0.15 & 3.507 & 12.49 \\
\hline $\mathrm{C} 1-3$ & 8 & 0.16 & 0.15 & 3.594 & 12.94 \\
\hline D1-1 & 10 & 0.2 & 0.15 & 3.406 & 10.81 \\
\hline D1-3 & 10 & 0.2 & 0.15 & 3.558 & 11.07 \\
\hline E1-2 & 12 & 0.24 & 0.15 & 3.539 & 10.49 \\
\hline E1-3 & 12 & 0.24 & 0.15 & 3.461 & 9.02 \\
\hline O2-1 & 0 & 0 & 0.3 & 5.817 & 26.35 \\
\hline $\mathrm{O} 2-2$ & 0 & 0 & 0.3 & 5.846 & 26.49 \\
\hline A2-1 & 4 & 0.08 & 0.3 & 5.607 & 25.85 \\
\hline A2- 4 & 4 & 0.08 & 0.3 & 5.524 & 25.82 \\
\hline B2-2 & 6 & 0.12 & 0.3 & 5.832 & 23.36 \\
\hline B2-3 & 6 & 0.12 & 0.3 & 5.907 & 25.05 \\
\hline C2-1 & 8 & 0.16 & 0.3 & 6.038 & 23.47 \\
\hline $\mathrm{C} 2-3$ & 8 & 0.16 & 0.3 & 5.992 & 23.36 \\
\hline D2-2 & 10 & 0.2 & 0.3 & 6.022 & 22.51 \\
\hline D2-4 & 10 & 0.2 & 0.3 & 5.896 & 20.6 \\
\hline E2-1 & 12 & 0.24 & 0.3 & 5.883 & 18.75 \\
\hline E2-2 & 12 & 0.24 & 0.3 & 6.006 & 20.89 \\
\hline O3-1 & 0 & 0 & 0.5 & 7.907 & 31.15 \\
\hline O3-2 & 0 & 0 & 0.5 & 8.205 & 31.60 \\
\hline A3-1 & 4 & 0.08 & 0.5 & 8.232 & 29.19 \\
\hline A3-2 & 4 & 0.08 & 0.5 & 8.252 & 29.21 \\
\hline B3-1 & 6 & 0.12 & 0.5 & 8.346 & 29.28 \\
\hline B3-2 & 6 & 0.12 & 0.5 & 8.33 & 29.21 \\
\hline C3-1 & 8 & 0.16 & 0.5 & 8.337 & 28.57 \\
\hline C3-3 & 8 & 0.16 & 0.5 & 8.202 & 28.81 \\
\hline D3-1 & 10 & 0.2 & 0.5 & 8.33 & 26.55 \\
\hline D3-3 & 10 & 0.2 & 0.5 & 8.289 & 25.85 \\
\hline E3-1 & 12 & 0.24 & 0.5 & 8.352 & 22.03 \\
\hline E3-2 & 12 & 0.24 & 0.5 & 8.202 & 22.31 \\
\hline
\end{tabular}

(Figure 3). As can be seen from Figure 3, the superimposed wave (Inc $+\mathrm{Re}$ ) of the incident wave (Inc) and the reflected wave $(\mathrm{Re})$ virtually coincide with the transmitted wave (Tra), indicating that the specimen reached stress equilibrium during the loading process.

3.2. Dynamic Tensile Stress-Time Curve. The dynamic tensile stress-time curve of the specimen was obtained using the tensile stress obtained through the conversion of the corresponding signals. In the same series of test results, the data with the largest scatter were discarded, leaving the data at intermediate values to represent the test results of that series of specimens. Figure 4 shows the typical dynamic tensile stress-time curves of specimens under different conditions. As can be seen from the figure, the behaviors of the dynamic tensile stress-time curves of the ring specimens with different $d / D$ values are consistent. Unlike the dynamic tensile stress-time curve of the solid disc specimen, which has a single peak, the stress-time curves of the ring specimens have

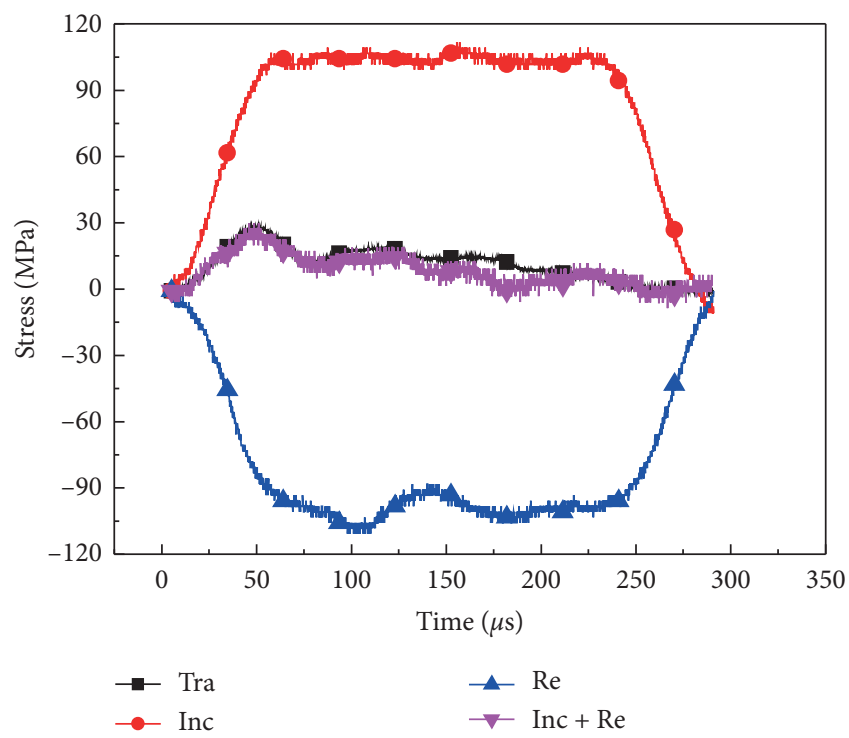

Figure 3: Typical stress equilibrium curves of the specimen. 


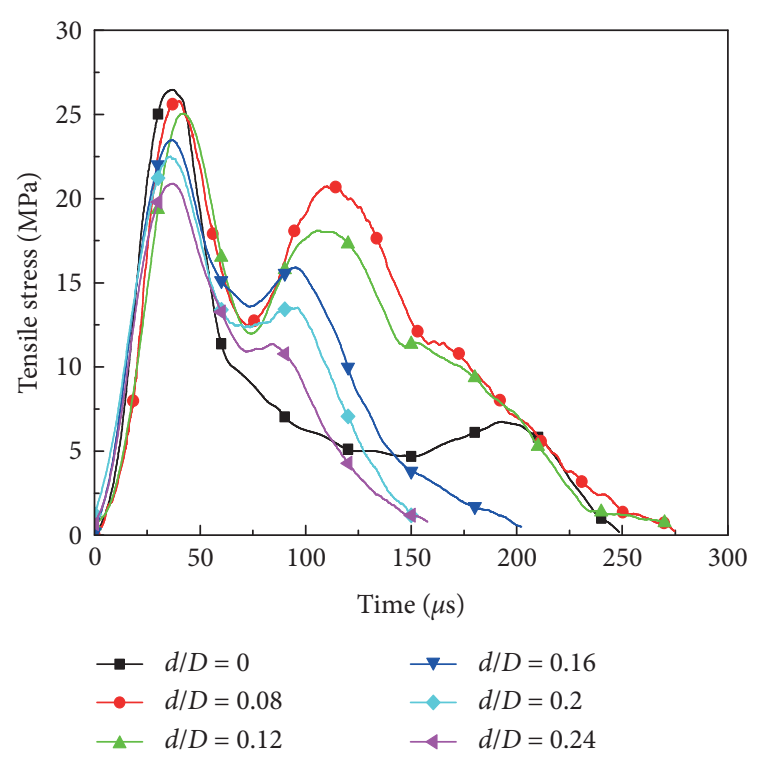

(a)

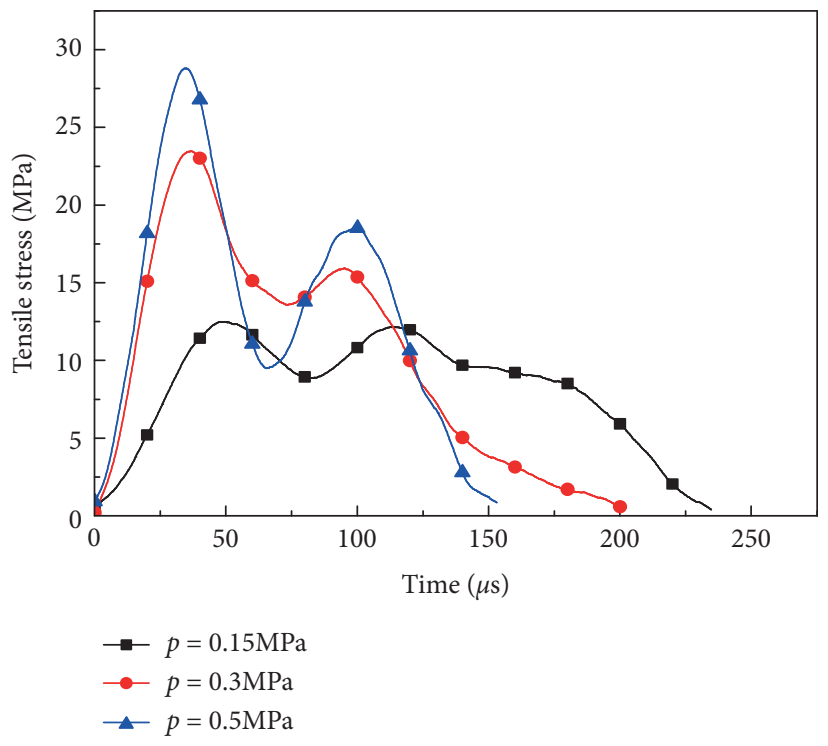

(b)

FIgURE 4: Tensile stress-time curves of specimens under (a) different hole diameters at the $0.3 \mathrm{MPa}$ pressure and (b) different pressures at the ratios of inner and outer diameter 0.16 .

double peaks, and after the first peak in the stress-time curves, the stress begins to unload. Because the specimens did not completely break, the specimens still had a certain load-bearing capacity. As the loading continued, a second peak with a lower stress value than the stress of the first peak appeared. Under the same gas gun pressure, as the hole diameter increased, the first peak stress (i.e., the dynamic tensile peak stress of the specimen) gradually decreased; the second peak stress also decreases and tended to level off; and it took less time for the second peak to appear. The reason of these behaviors is as follows. For the same gas gun pressure, the impact energy loaded onto a specimen was constant. As the diameter of the central hole decreased, the energy required for the initiation and propagation of the initial microdefects (microcracks and microcavities) in the rock specimen decreased, resulting in a decrease in the ability of the specimen to resist dynamic failure.

For the rock specimens with the same hole diameters, as the gas gun pressure increased, the dynamic tensile peak stress increased and the time it took to reach the peak stress decreased significantly. In addition, the second peak stress increased, and the time it took to reach the second peak stress decreased. This occurred because as the impact pressure increased, the initial defects contained in the specimen did not have enough time to close, causing the specimen to enter the plastic phase earlier, and, thus, the peak stress occurred earlier [23] and deformation hysteresis stress occurred, which led to an increase in the tensile strength of the specimen [25].

Figure 5 shows the different stages of the dynamic tensile stress-time curve of a typical ring specimen. As can be seen, before the formation of the second peak, the stress-time curve of the ring disc is consistent with that of the solid disc specimen. The peak stresses of all of the specimens

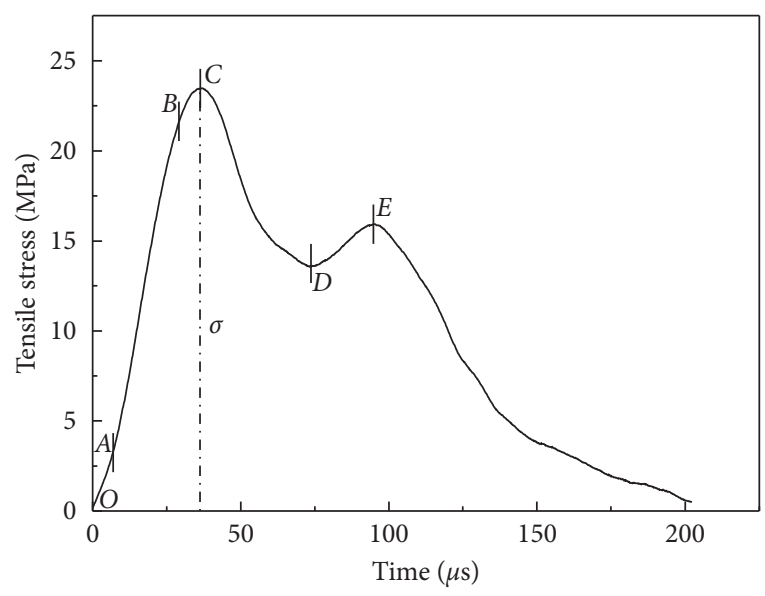

FIgURE 5: Different stages in the typical tensile stress-time curves of precentral holes discs specimens.

experienced the following four stages. Stage I is the compaction stage (Segment OA). Because the natural sandstone material contained initial defects, the rate of increase of the tensile stress of the specimen during the compaction stage increased, and the stress-time curves of this stage bent upward. Stage II is the linear deformation stage (Segment $\mathrm{AB})$. During this stage, the specimen underwent linear elastic deformation, and the internal strain energy of the rock began to increase rapidly but not enough to initiate cracks in the rock. The structure and properties of the rock were basically reversible in this stage. Stage III is the crack initiation and propagation stage (Segment BC). In this stage, the initial internal defects in the specimen had been compacted, the ability of the specimen to withstand tensile loads was enhanced, the rate of increase of the tensile stress 
decreased, and the stress-time curve bent downward. The rock was ductile in this stage. Point $B$ is the transition point at which the rock transitioned from being elastic to being ductile. Point $\mathrm{C}$ corresponds to the peak stress, where the rock transitioned from being brittle to being plastic. Stage IV is the unloading stage (Segment CD). In this stage, having passed the peak, the tensile stress rapidly decreased until the second peak was formed, and the internal stress of the specimen was redistributed under continued loading.

3.3. Dynamic Peak Stress. Figure 6 shows the trend in the dynamic peak stress variation with increasing $d / D$, which can be fitted using the following nonlinear functions:

$$
\sigma=\left\{\begin{array}{c}
62.66 e^{-\left(\frac{d / D+1.3}{1.15}\right)^{2}}, R^{2}=0.992(p=0.15 \mathrm{MPa}), \\
27.24 e^{-\left(\frac{d / D+0.1}{0.68}\right)^{2}}, R^{2}=0.985(p=0.3 \mathrm{MPa}), \\
31.37 e^{-\left(\frac{d / D-0.02}{0.39}\right)^{2}}, R^{2}=0.949(p=0.5 \mathrm{MPa}) .
\end{array}\right.
$$

As can be seen from Figure 6, when the gas gun pressure was $0.15 \mathrm{MPa}, 0.3 \mathrm{MPa}$, and $0.5 \mathrm{MPa}$, the dynamic peak stresses of the specimens decreased nonlinearly with increasing $\mathrm{d} / D$. The smaller the gas gun pressure applied, the smaller the dynamic peak stress of the specimen. It was observed that when the gas gun pressure was $0.15 \mathrm{MPa}$, the trend in the fitted curve did not resemble those of the curves when the gas gun pressures were $0.3 \mathrm{MPa}$ and $0.5 \mathrm{MPa}$. For a gas gun pressure of $0.15 \mathrm{MPa}$, the fitted curve exhibited a downward trend, while, for gas gun pressures of $0.3 \mathrm{MPa}$ and $0.5 \mathrm{MPa}$, the fitted curves exhibited upward trends. This is because the dynamic strength of the rock has a significant strain rate effect. When the gas gun pressure was low, the tensile stress of the specimen increased slowly, the largest defects in the rock developed with certain orientations, and the deformation of the other defects was not the main factor in the fracturing of the specimen. When the impact speed was high, the tensile stress of the specimen increased very rapidly, and then a single defect and the stress relaxation area around the defect were unable to propagate quickly enough to prevent other small defects or poorly oriented defects from being subsequently activated [6]. According to the results of previous studies, the specimen strain rate in SHPB dynamic mechanical tests is positively correlated with the impact pressure [23], so the trend in the mechanical characteristics of the specimen under the impact pressure can be used to represent the strain rate effect of the rock material.

3.4. Failure Modes. Figure 7 shows the failure modes of the specimens with different $d / D$ values for different gas gun pressures. For the solid disc specimens, the failure modes

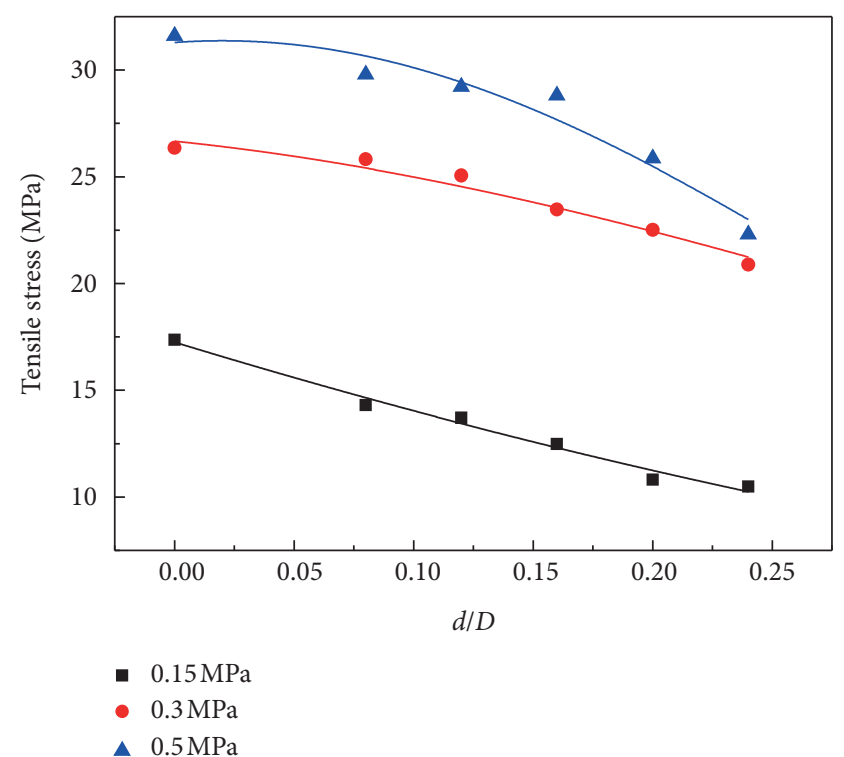

FIgURE 6: Relationship between dynamic tensile strength and hole diameter of specimen.

under the loading caused by the three gas gun pressures were basically the same, which is schematically shown in Figure 8. That is, a crack formed through the specimen and was aligned with the loading direction of the specimen. In addition, four semielliptical split blocks were formed symmetrically around this crack, and the shapes of the blocks at the loading points were more like tetrahedrons than ellipsoids. As the gas gun pressure increased, the failure mode of each specimen was different. Under a gas gun pressure of $0.15 \mathrm{MPa}$, the cracks through all of the split blocks extend to the center of the specimen along the loading direction, but they did not converge at the center of the specimen. The through cracks were narrow, and the centers of the two semicircular blocks that eventually formed still merged together well, indicating that the tensile fracturing caused by the tensile load occurred in the specimen. As the gas gun pressure increased, the four semielliptical split blocks merged at the center of the specimen, the volumes of the split blocks increased, the through cracks widened, and the wedge-shaped areas near the two loading points appeared crushed. This is because as the gas gun pressure increased, microcracks were formed in the areas near the two loading points due to the combined action of tension and shear, and they expended toward each other under the continued loading, eventually leading to the formation of fractures in the split blocks in these areas which evolved into the coexistence of tensile failure and local shear failure. Gong [26] and Cao et al. [27] demonstrated this point, which to a certain extent validates our test results.

For the ring specimens, the failure modes of the specimens with five different $d / D$ values under the three gas gun pressure loads are schematically shown in Figure 9. As can be seen, all of the main fracture surfaces are split and penetrate along the loading direction. The failure modes of the ring specimens did not change much with increasing gas gun pressure, but they did differ with increasing $d / D$. 


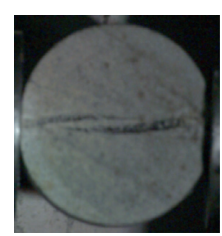

(a)

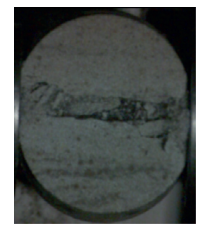

(g)

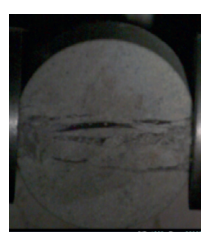

(m)

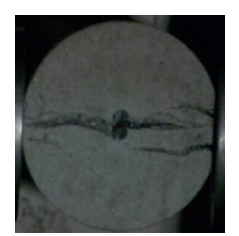

(b)

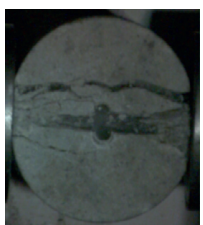

(h)

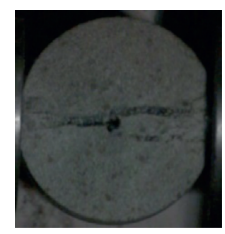

(n)

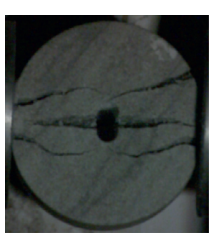

(c)

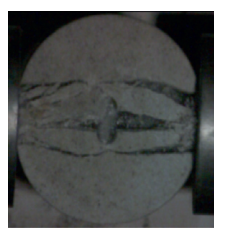

(i)

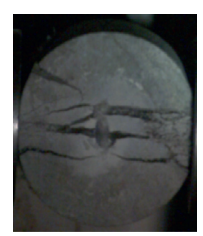

(o)

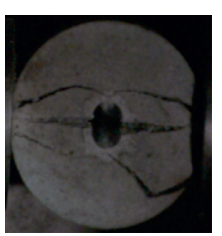

(d)

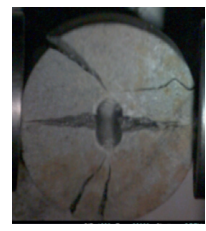

(j)

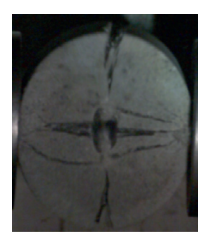

(p)

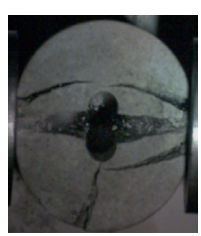

(e)

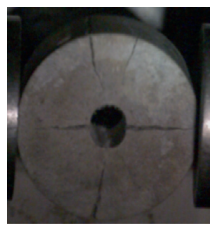

(k)

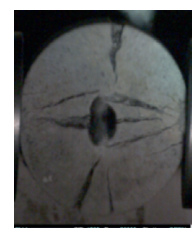

(q)

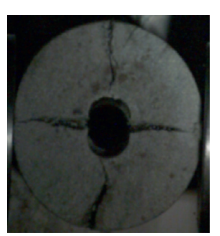

(f)

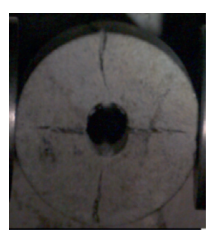

(1)

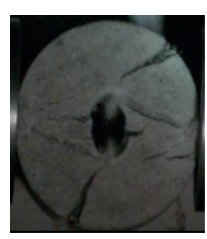

(r)

FIgURE 7: Final failure modes of sandstone specimens: (a) $p=0.15 \mathrm{MPa}, d / D=0$; (b) $p=0.15 \mathrm{MPa} d / D=0.08$; (c) $p=0.15 \mathrm{MPa}, d / D=0.12$; (d) $p=0.15 \mathrm{MPa}, d / D=0.16$; (e) $p=0.15 \mathrm{MPa}, d / D=0.2$; (f) $p=0.15 \mathrm{MPa}, d / D=0.24$; (g) $p=0.3 \mathrm{MPa}, d / D=0$; (h) $p=0.3 \mathrm{MPa}, d /$ $D=0.08$; (i) $p=0.3 \mathrm{MPa}, d / D=0.12$; (j) $p=0.3 \mathrm{MPa}, d / D=0.16$; (k) $p=0.3 \mathrm{MPa}, d / D=0.2$; (l) $p=0.3 \mathrm{MPa}, d / D=0.24$; (m) $p=0.5 \mathrm{MPa}$, $d / D=0 ;$ (n) $p=0.5 \mathrm{MPa} d / D=0.08$; (o) $p=0.5 \mathrm{MPa}, d / D=0.12$; ( $) p=0.5 \mathrm{MPa}, d / D=0.16$; (q) $p=0.5 \mathrm{MPa}, d / D=0.2 ;(\mathrm{r}) p=0.5 \mathrm{MPa}, d /$ $D=0.24$

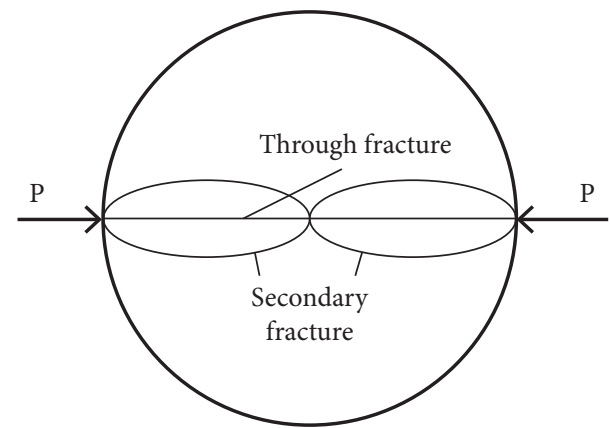

FIGURE 8: Simplified failure mode of complete disc specimens.

Under a gas gun pressure of $0.15 \mathrm{MPa}$, when $d / D<0.2$, the failure mode of the specimen can be simplified as type $A$, as shown in Figure 9(a), and when $d / D>0.2$, the failure mode of the specimen can be simplified as type $B$, as shown in Figure 9(b). For the type A failure mode, the final failure mode was consistent with that of the solid disc specimen, that is, a combination of tensile failure and local shear failure. As $d / D$ increased under these testing conditions, the tensile stress increased on the wall of the inner hole of the specimen where the tensile stress was concentrated, resulting in an increase in the width of the through crack. For type B failure mode, in addition to the through cracks in the loading direction, the specimen also contained a pair of secondary cracks that were approximately perpendicular to the through cracks. The two loading points of the specimen formed small wedge-shaped broken areas due to compressive shear. The secondary cracks formed after the main cracks were initiated due to the change in the stress propagation path inside the specimen caused by the hole effect. This resulted in the tensile stress being concentrated on the upper (lower) boundary of the upper (lower) part, thus leading to tensile failure, which expanded to the center of the hole. When $d / D=0.2$, the failure mode of the specimen was between type $\mathrm{A}$ and type $\mathrm{B}$, indicating that, at a gas gun pressure of $0.15 \mathrm{MPa}, 0.2$ is the critical $\mathrm{d} / D$ value. When $d / D<0.2$, the specimens experienced type A failure, and when $d / D>0.2$, the specimens experienced type B failure. Under a gas gun pressure of $0.3 \mathrm{MPa}$, when $d / D<0.16$, the specimens experienced type A failure, and when $d / D>0.16$, the specimens experienced type $B$ failure. Thus, at a gas gun pressure of $0.3 \mathrm{MPa}$, the critical $\mathrm{d} / D$ value is 0.16 . Under a gas gun pressure of $0.5 \mathrm{MPa}$, when $d / D<0.16$, the failure mode of the specimen was type $\mathrm{A}$, and when $d / D \geq 0.16$, the failure mode of the specimen was type B. For type A failure mode, a through crack appeared in the loading direction of the specimen. Four semielliptical split blocks formed symmetrically about the through crack. For the type B failure model, unlike at gas gun pressures of $0.15 \mathrm{MPa}$ and $0.3 \mathrm{MPa}$, there were four secondary cracks, which extended from the loading points and from the upper and lower ends of the specimen to the inner hole. This shows that as $d / D$ increased, the free surface of the through fractures gradually became larger. When the critical $d / D$ value was exceeded, no secondary cracks formed almost perpendicular to the loading direction, and the circular central hole's effect increased the free surfaces of the macroscopic fractures. As the gas gun pressure increased, the failure modes of the specimens were still type A or type $\mathrm{B}$, and the critical $d / D$ value decreased accordingly. That is, the circular central hole increasingly affected the free 


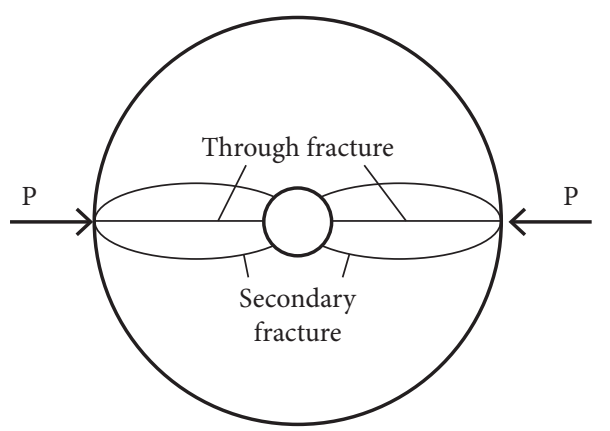

(a)

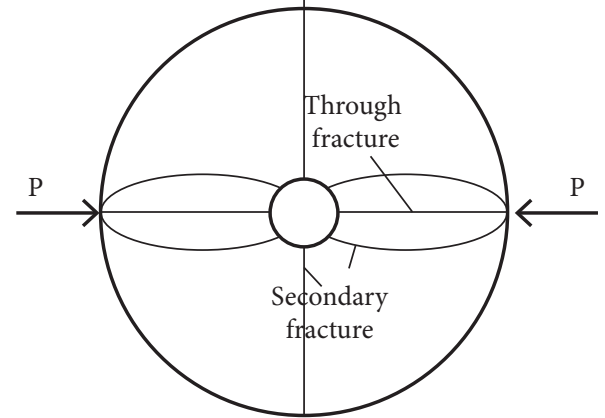

(b)

FIgURE 9: Simplified failure modes of precentral hole disc specimens under (a) type A and (b) type B.

surfaces of the macroscopic fractures due to the effect of the strain rate of the rock.

\section{Conclusions}

In this study, $\Phi 50 \mathrm{~mm}$ SHPB test system was used to conduct impact splitting tests at $0.15 \mathrm{MPa}, 0.3 \mathrm{MPa}$, and $0.5 \mathrm{MPa}$ on solid sandstone disc specimens and ring sandstone disc specimens with inner-to-outer diameter ratios, $d / D$, of 0.08 , $0.12,0.16,0.2$, and 0.24 . The following conclusions were drawn from the results of these experiments.

(1) Compared with the solid disc specimens, the dynamic tensile stress-time curves of the ring specimens exhibited a typical double peak behavior, and the second peak stress was smaller than the first.

(2) The $d / D$ values and the gas gun pressures had significant effects on the dynamic peak stresses of the ring specimens. Under the three gas gun pressures, with increasing $\mathrm{d} / D$, the dynamic peak stresses of the specimens exhibited significant nonlinear decreases. The extent of the decrease in dynamic peak stresses of the specimens with different $\mathrm{d} / D$ values at $0.15 \mathrm{MPa}$ was less than those at $0.3 \mathrm{MPa}$ and $0.5 \mathrm{MPa}$, suggesting a noticeable strain rate effect.

(3) The failure modes of the specimens were not significantly affected by the gas gun pressure, but they varied with $d / D$. For the solid disc specimens, as the gas gun pressure increased, the specimens evolved from tensile failure to a combination of tensile failure and local shear failure. For the ring specimens, under the same gas gun pressure, the failure mode also changed from type A to type $B$, which was the same as in the solid disc specimens. In addition to the through cracks in the loading direction, a pair of secondary cracks formed nearly perpendicular to the through cracks. As d/D increased, the volumes of the four semielliptical split blocks, which formed symmetrically about the through cracks, increased. When the gas gun pressures were $0.15 \mathrm{MPa}, 0.3 \mathrm{MPa}$, and $0.5 \mathrm{MPa}$, the critical $\mathrm{d} / D$ values for the specimens, that is, the values at which the specimens transitioned from A-type failure mode to B-type failure mode, were $0.2,0.16$, and 0.16 , respectively.

\section{Data Availability}

All the data used to support the findings of this study are included within the article.

\section{Conflicts of Interest}

The authors declare that there are no conflicts of interest in the publication of this paper.

\section{Authors' Contributions}

Jiehao $\mathrm{Wu}$ analyzed the data and wrote the manuscript, Qi Zong completed the method design, and Ying Xu revised the manuscript.

\section{References}

[1] L. Yuan, "Research progress on risk identification, assessment, monitoring and early warning technologies of typical dynamic hazards in coal mines," Journal of China Coal Society, vol. 45, no. 5, pp. 1557-1566, 2020.

[2] D. Y. Li, Z. Y. Han, X. L. Sun, and L. B. Li, "Characteristics of dynamic failure of marble with artificial flaws under split Hopkinson pressure bar tests," Chinese Journal of Rock Mechanics and Engineering, vol. 36, no. 12, pp. 2872-2883, 2017.

[3] Q. Zhang, D. Ma, J. Liu, K. Zhang, and Z. Fan, "Numerical studies on the failure process of heterogeneous rock material with preexisting fracture under uniaxial compression," $A d-$ vances in Civil Engineering, vol. 2018, pp. 1-12, 2018.

[4] X. Chen, Q. Yang, and D. J. Li, Study on the Mechanical Effect of Anisotropic Damage in Fracture Network of Rock Mass, Science Press, Beijing, China, 2016.

[5] H. Haeri, A. Khaloo, and M. F. Marji, "Fracture analyses of different pre-holed concrete specimens under compression," Acta Mechanica Sinica, vol. 31, no. 6, pp. 855-870, 2015.

[6] A. M. Rubin and T. J. Ahrens, "Dynamic tensile-failure-induced velocity deficits in rock," Geophysical Research Letters, vol. 18, no. 2, pp. 219-222, 1991.

[7] D. W. Hobbs, "The tensile strength of rocks," International Journal of Rock Mechanics and Mining Sciences \& Geomechanics Abstracts, vol. 1, no. 3, pp. 385-396, 1964.

[8] J. A. Hudson, "Tensile strength and the ring test," International Journal of Rock Mechanics and Mining Sciences \& Geomechanics Abstracts, vol. 6, no. 1, pp. 91-97, 1969. 
[9] M. Mellor and I. Hawkes, "Measurement of tensile strength by diametral compression of discs and annuli," Engineering Geology, vol. 5, no. 3, pp. 173-225, 1971.

[10] D. W. Hobbs, "An assessment of a technique for determining the tensile strength of rock," British Journal of Applied Physics, vol. 16, no. 2, pp. 259-268, 1965.

[11] C. S. Chen and S. C. Hsu, "Measurement of indirect tensile strength of anisotropic rocks by the ring test," Rock Mechanics and Rock Engineering, vol. 34, no. 4, pp. 293-321, 2001.

[12] W. C. Zhu, D. Feng, K. T. Chau, and C. A. Tang, "Numerical test using ring specimen as medium to determine indirect tensile strength of rock," Journal of Northeastern University (Natural Science), vol. 25, no. 9, pp. 899-902, 2004.

[13] M. Q. You, X. L. Chen, and C. D. Su, "Brazilian splitting strengths of discs and rings of rocks in dry and saturated conditions," Chinese Journal of Rock Mechanics and Engineering, vol. 30, no. 3, pp. 464-472, 2011.

[14] Q. H. Wu, F. J. Zhao, X. B. Li, S. M. Wang, B. Wang, and Z. H. Zhou, "Mechanical properties of ring specimens of sandstone subjected to diametral compression," Rock and Soil Mechanics, vol. 39, no. 11, pp. 3969-3975, 2018.

[15] Q. H. Wu, L. Weng, Y. L. Zhao, F. J. Zhao, W. Q. Peng, and S. P. Zhang, "Deformation and cracking characteristics of ring-shaped granite with inclusion under diametrical compression," Arabian Journal of Geosciences, vol. 13, no. 14, p. 681, 2020.

[16] S. Q. Yang, "Particle flow analysis of macroscopic and microscopic mechanical properties of Brazilian disc containing a hole under splitting test," Journal of China University of Mining \& Technology, vol. 48, no. 5, pp. 984-992, 2019.

[17] Q.-S. Bai, S.-H. Tu, and C. Zhang, "DEM investigation of the fracture mechanism of rock disc containing hole(s) and its influence on tensile strength," Theoretical and Applied Fracture Mechanics, vol. 86, pp. 197-216, 2016.

[18] X. P. Zhou, L. F. Wang, and Y. D. Shou, "Understanding the fracture mechanism of ring Brazilian disc specimens by the phase field method," International Journal of Fracture, vol. 226, no. 1, pp. 17-43, 2020.

[19] D.-Y. Li, T. Wang, T.-J. Cheng, and X.-L. Sun, "Static and dynamic tensile failure characteristics of rock based on splitting test of circular ring," Transactions of Nonferrous Metals Society of China, vol. 26, no. 7, pp. 1912-1918, 2016.

[20] X. B. Li, Q. H. Wu, M. Tao, L. Weng, L. J. Dong, and Y. Zou, "Dynamic Brazilian splitting test of ring-shaped specimens with different hole diameters," Rock Mechanics and Rock Engineering, vol. 49, no. 10, pp. 4143-4151, 2016.

[21] X. Li, F. Feng, and D. Li, "Numerical simulation of rock failure under static and dynamic loading by splitting test of circular ring," Engineering Fracture Mechanics, vol. 188, pp. 184-201, 2018.

[22] ISRM, "Suggested methods for determining tensile strength of rock materials," International Journal of Rock Mechanics and Mining Sciences \& Geomechanics Abstracts, vol. 15, no. 3, pp. 99-103, 1978.

[23] X. B. Li, Rock Dynamics: Fundamentals and Applications, Science Press, Beijing, China, 2014.

[24] Y. X. Zhou, K. Xia, X. B. Li et al., "Suggested methods for determining the dynamic strength parameters and mode-I fracture toughness of rock materials," International Journal of Rock Mechanics and Mining Sciences, vol. 49, pp. 105-112, 2012.

[25] D. B. Han, G. M. Zhao, X. R. Meng, and W. W. Ma, "Study on dynamic mechanical properties of sandstone under high strain rate," Blasting, vol. 31, no. 2, pp. 8-13, 2014.
[26] F. G. Gong, Experimental Study on Rock Mechanical Property and Dynamic Strength Criteria under Coupled Static and Dynamic Loads, M.D. dissertation, Central South University, Changsha, China, 2010.

[27] L. L. Cao, H. Pu, M. Li, and X. M. Mao, "Experimental research on the dynamic tensile fracture and the energy dissipation characteristics of coal-serial sandstone," Journal of China Coal Society, vol. 42, no. 2, pp. 492-499, 2017. 